\title{
A Long-term synoptic-scale climate study over Mariepskop, Mpumalanga, South Africa
}

\author{
Ilze Pretorius ${ }^{1}$ and Hannes Rautenbach ${ }^{1}$
}

${ }^{1}$ Department of Geography, Geoinformatics and Meteorology, University of Pretoria

\begin{abstract}
Mariepskop forms part of the northernmost edge of the Drakensberg Mountain range and is known for its complex topography associated with meso-scale atmospheric circulation, and therefore its numerous climatic zones. The mountain hosts a high biodiversity. The peak of Mariepskop lies at approximately 1900m Above Mean Sea Level (AMSL), which is higher than the surrounding escarpment to the east. Its foothills also extend well into the Lowveld at about $700 \mathrm{~m}$ AMSL. Mariepskop is therefore ideal for studying airflow exchange between the industrial Highveld and the Lowveld with its diversity of natural resources. It is also ideal for detecting global warming signals on altitudinal gradients extending from the Lowveld to altitudes above the Highveld escarpment. In this study long-term National Centre for Atmospheric Research / National Centre for Environmental Prediction (NCAR/NCEP) wind data at two atmospheric pressure levels ( 850 and $700 \mathrm{hPa}$ ), as well as near-surface temperature data, were obtained for the Mariepskop region for the summer (December-January-February: DJF (1981-2011)) and winter (June-July-August: JJA (1980-2012)) seasons. The data was used to study synoptic wind flow across the mountain in the upper (700 $\mathrm{hPa}$ ) and lower $(800 \mathrm{hPa}$ ) atmosphere, as well as near-surface temperature gradients. During the summer season, east-south-easterly and south-easterly winds were found to be the most prominent. These winds are commonly associated with both continental and ridging anticyclonic conditions. During winter, the predominant wind direction at $850 \mathrm{hPa}$ is south-easterly, which is also due to the influence of ridging anticyclones, while at $700 \mathrm{hPa}$ the dominant winter wind direction becomes west-south-west, which is due to the more frequent eastward passing of cyclonic frontal systems across the Highveld towards the Lowveld. Long-term near-surface temperatures exhibit a weak increasing linear temperature trend for both seasons, which might be due to global warming.
\end{abstract}

Keywords: Lowveld, global warming, climate change, mountain climate, Mariepskop

\section{$1 \quad$ Background}

Changes in global temperatures, and sometimes climate, have been widely observed over the past 150 years, including in South Africa (IPCC 2007). Because of the long-term nature of global warming, it is not only crucial to establish sustainable climate recording sites, but also to ensure that the impact of global warming on a diversity of conditions (e.g. various topographical profiles, vertically changing atmospheric stabilities and biodiversity) could be studied at such sites.

Study sites in the vicinity, or on high mountains are ideal, since climates can be studied on both horizontal and vertical scales. Future global warming might result in more surface evaporation associated with cooling, while temperature increases will be more profound at condensation levels (cloud bases) where temperatures will increase as a result of latent heat fluxes from the ground. Shifts in vertical climatic zones are also more detectable on high mountains. For instance, studies on Mount Kilomanjaro revealed altitudinal shifts in ecological zones on the slopes of the mountain (Hemp 2005). The importance of mountains as areas of ecological monitoring has also been emphasized through the activities of institutions such as the African Highlands Initiative (AHI) in Ethiopia, as well as many activities of the International Mountain Society (IMS) (Switzerland) and the Mountain Research Initiative (MRI) (Switzerland).
Mariepskop, with its location at longitude $24^{\circ} 32^{\prime} 34.57^{\prime \prime S}$ and latitude $30^{\circ} 52^{\prime} 07.38^{\prime \prime} \mathrm{E}$ and altitude of approximately $1900 \mathrm{~m}$ Above Mean Sea Level (AMSL), is located at the northern edge of the Drakensberg mountain range in the Mpumalanga Province of South Africa (Fig. 1). The mountain is characterized by complex topography associated with meso-scale atmospheric circulation and different climatic zones. It therefore hosts a high biodiversity. What makes Mariepskop an ideal study site is the fact that its peak is higher than the surrounding escarpment to the east, and that its foothills extend well into the Lowveld at about $700 \mathrm{~m} \mathrm{AMSL}$ and 231 $\mathrm{km}$ from the Indian Ocean. It is therefore ideal for studying airflow exchange between the industrialized Highveld and the Lowveld with its diversity of natural resources.

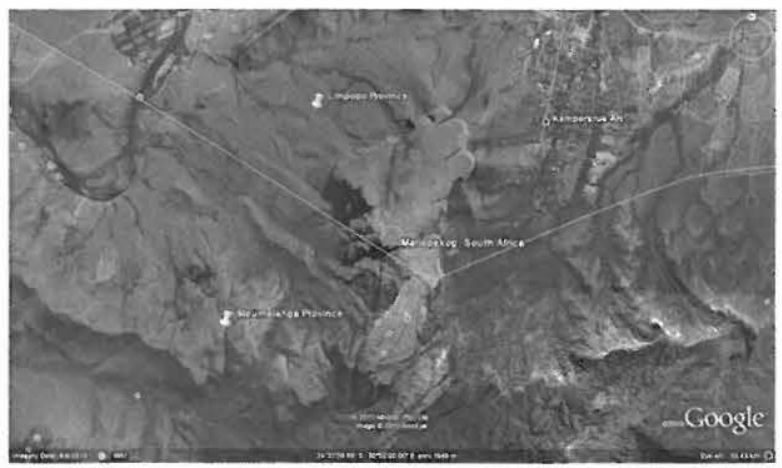

Fig. 1: The location of Mariepskop with reference to the Mpumalanga and Limpopo Provinces of South Africa. 
Ross et al. (2001) has categorised atmospheric synoptic systems that affect the Lowveld of Mpumalanga (where Mariepskop is situated) as (1) easterly waves/lows, (2) westerly disturbances (including troughs and cut-off lows) (3) ridging anticyclones and (4) continental anticyclones.

Tropical disturbances affecting South Africa, like easterly waves and lows, are predominantly summer systems (Tyson and Preston Whyte 2000). In contrast, westerly disturbances affecting South Africa are located more southwards and are predominantly more frequent during the winter (Garstang et al. 1996; Tyson et al. 1996; Ross et al. 2001). Ridging anticyclones associated with the eastwards passage of cold front systems occur relatively consistently throughout the year (Ross et. al. 2001), but with a higher frequency of occurrence in October and February (Tyson and Preston Whyte 2000). Continental anticyclones show a clear annual cycle with a peak occurrence during autumn and winter (Ross et al. 2001). For Mariepskop, it is especially ridging highs, associated with easterly onshore flow, and continental systems allowing for westerly flow towards the escarpment, that are important.

The objective of this study is to investigate the dominant long-term upper air (700 hPa pressure level) and surface ( $850 \mathrm{hPa}$ pressure level) synoptic scale wind patterns, as well as near-surface temporal variability, during the summer (December-JanuaryFebruary: DJF) and winter (June-July-August: JJA), at Mariepskop.

\section{Data and methods}

In this study long-term (1981 to 2011: 30 years) National Centre for Atmospheric Research / National Centre for Environmental Prediction (NCAR/NCEP) wind reanalysis data (Kalnay et al. 1996) at two atmospheric pressure levels (850 and $700 \mathrm{hPa}$ ), as well as near-surface temperature reanalysis data were obtained for the Mariepskop region for the summer (December-January-February: DJF) and winter (June-July-August: JJA) seasons. A disadvantage is that the spatial coverage of the data is at a course resolution of 2.5 degree $\times 2.5$. Nevertheless, NCAR/NCEP reanalysis data are the only data available for Mariepskop exhibiting a consistent long record at different levels in the vertical. The data were used to study synoptic wind flow across Mariepskop in the upper $(700 \mathrm{hPa})$ and lower $(800 \mathrm{hPa})$ atmosphere, as well as long-term near-surface temperature gradients.

A nearest neighbour weighting was employed in finding an average value at Mariepskop for each of the three NCAR/NCEP reanalysis variables (nearsurface temperature, u-wind and v-wind). The averaged $u$-wind and $v$-wind values were used to calculate wind direction and wind speed frequencies for the summer and winter seasons at the $850 \mathrm{hPa}$ and $700 \mathrm{hPa}$ levels. The Near-surface temperature values were used in an effort to detect historical trends.

\section{$3 \quad$ Wind frequency analysis}

The wind roses in Fig. 2 and 3 depict summer season wind directions and wind speed frequencies at Mariepskop at the $850 \mathrm{hPa}$ (left) and $700 \mathrm{hPa}$ (right) levels as calculated from a 30-year (1981-2011) data record.

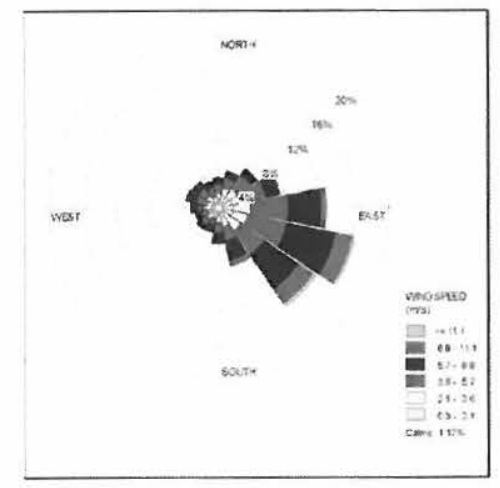

Fig. 2: Summer wind speed and direction frequencies for Mariepskop at the $850 \mathrm{hPa}$ pressure level as obtained from a 30-year (1981-2011) data record.

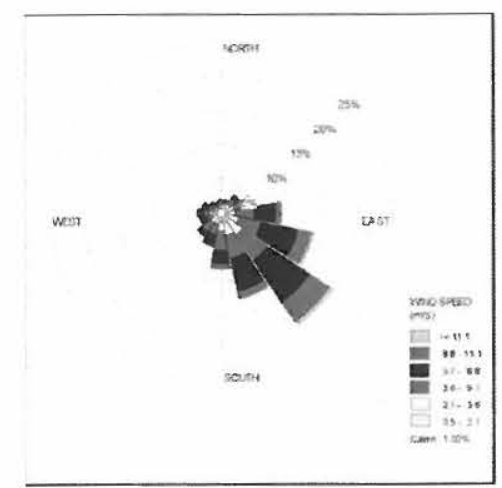

Fig. 3: Summer wind speed and direction frequencies for Mariepskop at the $700 \mathrm{hPa}$ pressure level as obtained from a 30-year (1981-2011) data record.

From Fig. 2 and 3 it is clear that the east-southeasterly and south-easterly wind directions are by far the most prominent. These findings agree well with the results of a study done on circulation for the period 1994-1998 over the Lowveld of South Africa by Ross et al. 2001. South-easterly winds normally occur in association with both continental and ridging anticyclonic circulation.

The long-term wind class frequency distribution of the $850 \mathrm{hPa}$ and $700 \mathrm{hPa}$ summer winds are indicated in Fig. 4 and 5 . The wind class frequency distribution histograms show the frequency of occurrence of different wind speed classes. Fig. 4 illustrates that the dominant wind speed class at the $850 \mathrm{hPa}$ level for summer is between $3.6-5.7 \mathrm{~m} / \mathrm{s}$, with a frequency of occurrence of $33 \%$. 
This class is followed by the $5.7-8.8 \mathrm{~m} / \mathrm{s}$ class, which prevails $25.6 \%$ of summer days. Calm days occur only about $1 \%$ of the time whereas winds greater or equal to $11.1 \mathrm{~m} / \mathrm{s}$ occur on $1.1 \%$ of summer days.

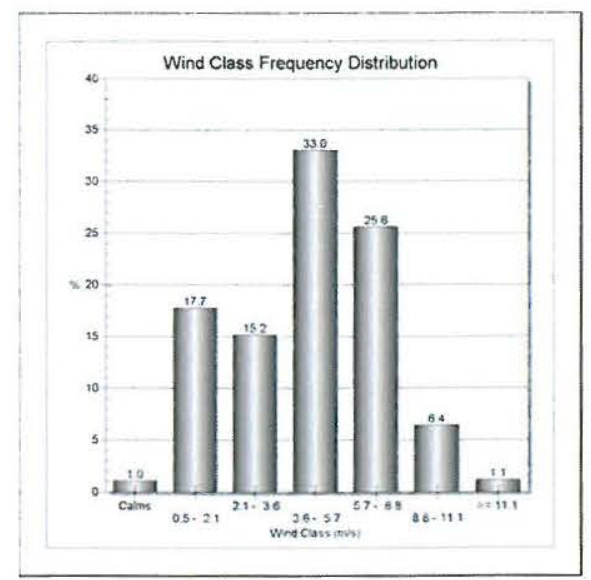

Fig. 4: Summer wind class frequency distribution for Mariepskop at the $850 \mathrm{hPa}$ pressure level as obtained from a 30-year (1981-2011) data record.

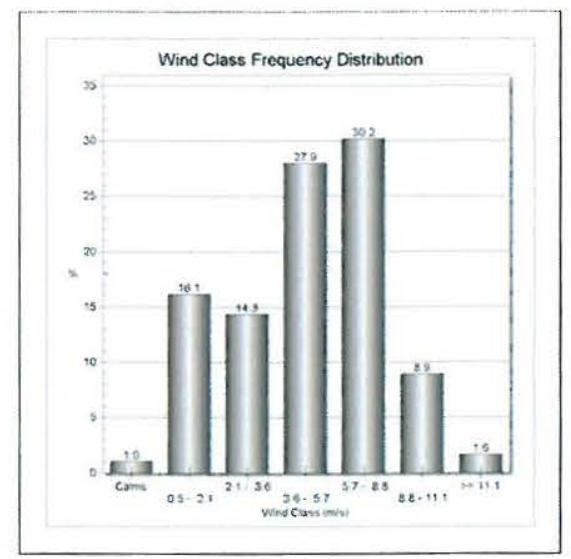

Fig. 5: Summer wind class frequency distribution for Mariepskop at the $700 \mathrm{hPa}$ pressure level as obtained from a 30-year (1981-2011) data record.

For the $700 \mathrm{hPa}$ level the two dominant summer wind speed classes are the $5.7-8.8 \mathrm{~m} / \mathrm{s}(30.2 \%)$ and 3.6 $5.7 \mathrm{~m} / \mathrm{s}(27.9 \%$ ) classes (Fig. 5). The wind speeds at the $700 \mathrm{hPa}$ level are therefore greater than at the $850 \mathrm{hPa}$ level. Calm days occur $1 \%$ of the time at the $700 \mathrm{hPa}$ level, which is the same as for the $850 \mathrm{hPa}$ level, and wind speeds above $11.1 \mathrm{~m} / \mathrm{s}$ are $0.5 \%$ more abundant at the $700 \mathrm{hPa}$ level, at $1.6 \%$.

High wind speeds exceeding $6 \mathrm{~m} / \mathrm{s}$ are often associated with ridging anticyclonic conditions. This is due to steep pressure gradients which induce strong moisture advection from the Indian Ocean.

The associated long-term wind roses for the winter season from the period 1980-2010 are shown in Fig.6 and 7 .

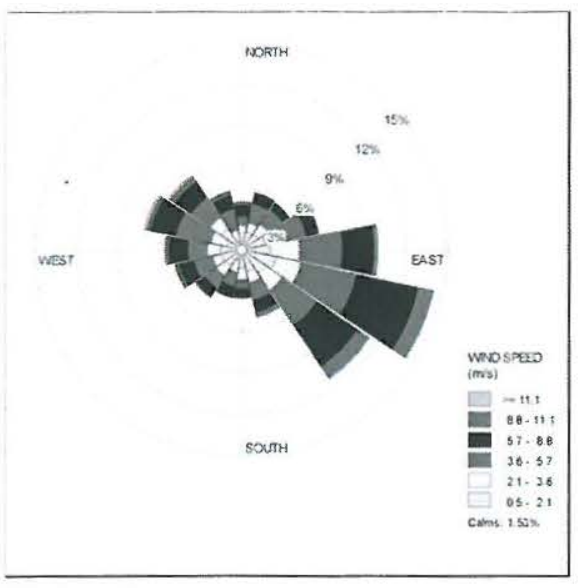

Fig. 6: Winter wind speed and direction frequencies for Mariepskop at the $850 \mathrm{hPa}$ pressure level as obtained from a 30-year (1981-2011) data record.

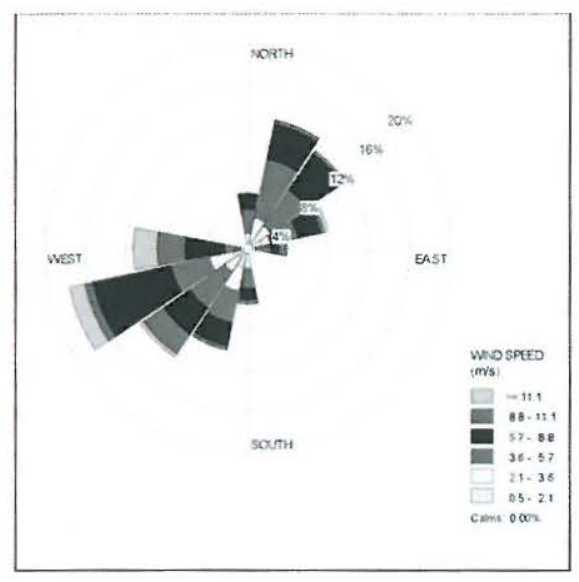

Fig. 7: Winter wind speed and direction frequencies for Mariepskop at the $700 \mathrm{hPa}$ pressure level as obtained from a 30-year (1981-2011) data record.

Both the $850 \mathrm{hPa}$ and $700 \mathrm{hPa}$ levels show a more varied wind direction distribution during winter, as compared to summer. At the $850 \mathrm{hPa}$ level the dominant wind directions are still east-south-east (around 14\%), south-east (around 11\%) and east (around $10 \%$ ), but a more prominent portion of the winds are directed west-north-west (around $8 \%$ ) and north-west (around 7\%) directions.

The $700 \mathrm{hPa}$ winter wind direction distribution differs significantly from the summer distribution. In this case the dominant wind direction is west-south-west $(18 \%)$, with equal proportions from the south-west and north-north-east (13\%), in second place. The winds from the west-south-west and south-west have the greatest wind speeds, with a relatively large proportion of the winds from these directions exceeding speeds of $11 \mathrm{~m} / \mathrm{s}$, whereas winds from the opposite direction reach these speeds less often.

The predominant south-easterly flow exhibited by the $850 \mathrm{hPa}$ winter wind rose is due to the influence of 
ridging anticyclones, which occur fairly evenly throughout the year. The north-westerly wind directions are caused by westerly waves and cold front propagation which affect the Lowveld mainly during the spring and winter seasons.

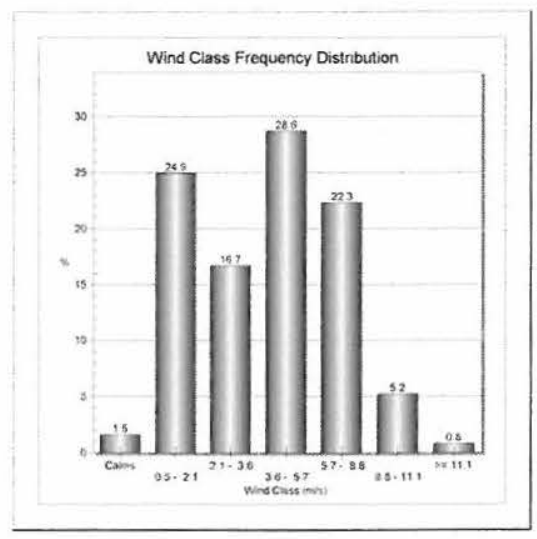

Fig. 8: Winter wind class frequency distribution for Mariepskop at the $850 \mathrm{hPa}$ pressure level as obtained from a 30-year (1981-2011) data record.

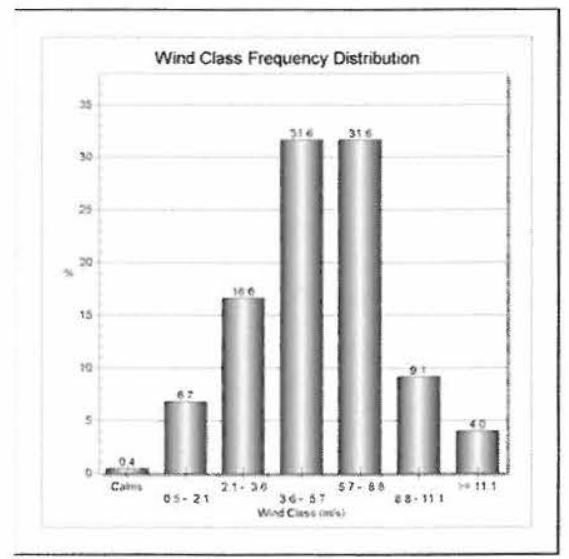

Fig. 9: Winter wind class frequency distribution for Mariepskop at the $700 \mathrm{hPa}$ pressure level as obtained from a 30-year (1981-2011) data record.

From Fig. 8 it is clear that the dominant wind speed class at an atmospheric level of $850 \mathrm{hPa}$ is the 3.6-5.7 $\mathrm{m} / \mathrm{s}$ class $(28.6 \%)$. At the $700 \mathrm{hPa}$ level the dominant wind speed classes are the $3.6-5.7 \mathrm{~m} / \mathrm{s}$ and $5.7-8.8$ $\mathrm{m} / \mathrm{s}$ classes each with a frequency of occurrence of $31.6 \%$ (Fig. 9). In general the winds at the $700 \mathrm{hPa}$ level reach higher speeds with $4 \%$ of total winds falling in the $>11.1 \mathrm{~m} / \mathrm{s}$ class (relative to the $0.8 \%$ at the $850 \mathrm{hPa}$ level). The $700 \mathrm{hPa}$ level experiences calm conditions only $0.4 \%$ of the time during winter, whereas the $850 \mathrm{hPa}$ level experiences these conditions $1.5 \%$ of the time.

\section{$4 \quad$ Near-surface temperature trends}

The average near-surface temperature was calculated for each summer and winter season from 1981-2011. The seasonal averages were then plotted and are displayed in Fig. 10 and 11. A Pearson correlation was employed relative to the averages of an increasing linear dataset with a slope of one in order to estimate whether an increasing trend exists in the data. The summer coefficient of determination of these two datasets is 0.19 , which means that $19 \%$ of the variation in the average summer temperature is attributable to an increasing trend in temperature. This is not statistically significant, meaning that one cannot conclude that a warming trend exists, although a moderate warming appears.

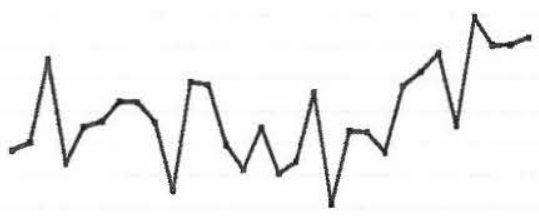

Fig. 10: Distribution of average summer near-surface temperatures over the past 30-years over Mariepskop

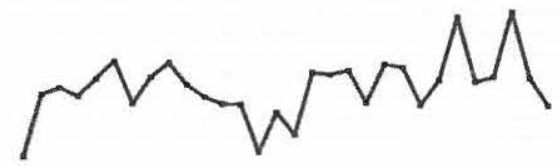

Fig. 11: Distribution of average winter near-surface temperatures over the past 30-years over Mariepskop.

The associated coefficient of determination for winter temperatures is 0.26 . There is thus also a weak increasing linear trend in the winter data, which is higher than the summer trend.

\section{Conclusions}

Long-term NCAR/NCEP reanalysis wind data was obtained over Mariepskop at two atmospheric pressure levels (850 and $700 \mathrm{hPa}$ ). Near-surface temperature data was also collected. It was found that east-south-easterly and south-easterly wind directions prevail at both pressure levels during the summer season, and occur in association with both continental and ridging anti-cyclonic conditions. During winter, the predominant wind direction at 850 $\mathrm{hPa}$ is south-easterly and is due to the influence of ridging anticyclones. At $700 \mathrm{hPa}$, however, the dominant wind direction is west-south-west. In nearsurface temperatures a weak increasing temperature trend was observed for both seasons. 
E. Kalnay, M. Kanamitsu, R. Kistler, W. Collins, D. Deaven, L. Gandin, M. Iredell, S. Saha, G. White, J. Woollen, Y. Zhu, M. Chelliah, W. Ebisuzaki, W. Higgins, J. Janowiak, K.C. Mo, C. Ropelewski, J. Wang, A. Leetmaa, R. Reynolds, R. Jenne, D. Joseph, (1996). 'The NMC/NCAR 40-Year reanalysis project', Bull. Am. Meteorol. Soc., 77, 437-471

NCEP Reanalysis data provided by the NOAA/OAR/ESRL PSD, Boulder, Colorado, USA, from their Website at http://www.esrl.noaa.gov/psd/, accessed April, 2011.

P. A. Reid, P. D. Jones, O. Brown, C. M. Goodess and T. D. Davies , (2001). 'Assessments of the reliability of NCEP circulation data and relationships with surface climate by direct comparisons with station based data ', Climate Research 17, 247-261.

Ross, K.E., Piketh, S.J., Swap, R.J. and Staebler, R.M., (2001). 'Controls governing airflow over the South African lowveld', South African Journal of Science, 97 , p. 29-40.

Tyson, P.D., Preston-Whyte, R.A., (2000). 'The Weather and Climate of South Africa', Oxford University Press South Africa, 2nd edition. 396 pp. 